\title{
RELATIVE STUDY OF WRITTEN ENGLISH LANGUAGE ERRORS AT HSSC LEVEL IN GOVERNMENT COLLEGES IN SINDH: COMPARISONOF RURAL AND URBAN SINDH
}

\author{
1.Imdadullah Jatoi,MS Scholar Mehran University of Engineering and Technology Jamshoro Sindh Pakistan. \\ 2.Madam Shabana Sartaj, Assistant Professor in English at Sindh Agricultural University Tando Jam Sindh \\ Pakistan.
}

3.Wazir Ali Kalhoro, MS Scholar Mehran University of Engineering and Technology Jamshoro Sindh Pakistan

4.Intikhab Panhanwar MS Scholar Mehran University of Engineering and Technology Jamshoro Sindh Pakistan

\begin{abstract}
Teaching English as a second language has always been a big challenge for teachers who offer their services at non-native settings. Moreover, it has not been less than a challenging for a teacher to teach error-free writing techniques to his or her students. It demands an extensive and untiring efforts to serve this purpose in terms of writing. The teachers in Pakistan always put their extra efforts to address the common grammar mistakes and errors committed by L2 learners in a target language. The study was set to investigate common English language errors made by public and private college students belonging to both urban and rural parts of Sindh, Pakistan. The study found out the most common and apparent grammatical errors in students' essays including passive voice, verb, tense, subject-verb agreement, prepositions, articles, plurals and auxiliaries. Besides, errors were identified categorically according to their classification. The study involved 60 students and 20 teachers who were free to express their attitudes and opinions towards L2 English writing skills. The findings revealed that there were various grammatical errors between the HSSC students of both urban and rural Sindh. All those errors were due to intra-lingual transfer. The study found out that intra-lingual transfer of errors were more rampant than the inter-lingual ones. In addition, the findings of study showed that the English writing skills of public colleges in Sindh need constant practice and drill. Based on the findings, it is recommended that educators, policymakers as well as ESL teachers can get an invaluable language benefit. Moreover; this study will give teachers an insight to be well prepared before their learners for the target language. Finally, it is hoped that findings of this study would be a greater assistance in developing English writing skills among secondary students in Sindh, Pakistan.
\end{abstract}

Keywords: Error analysis, Assessment, language learning, Language acquisition, English Second language, prepositions, grammatical errors, articles, passives, tenses, frequency of occurrence.

DOI: $10.7176 /$ RHSS/11-14-08

Publication date:July $31^{\text {st }} 2021$

\section{CHAPTER 1 \\ INTRODUCTION}

\subsection{INTRODUCTION}

Learning or writing has got crucial value in our daily life, especially when we talk about second language learning development. In simple words, it will be very hard to live without learning English as a second language (ESL). We cannot take our written English errors easy as ESL learners cannot improve their writing skills without making errors. That is why errors are considered a back bone of language learning process. While 
defining incidence, nature, reasons or consequences of unsuccessful process of language learning would prove fruitful for ESL learners (James, 1998). As a matter of written skills, the errors that are committed by ESL students have been categorized in two kinds: (1) errors depending on organization (2) errors depending on grammar (Kroll, 1994). Organizational errors have been connected to written content. on the other hand, grammatical errors have been related to grammatical incorrectness. This will give direction to unsuccessful process of language. This study will highlight errors related to grammar.

Focusing on combined skills of learners, the writing skill always gives tough time to English language learners or foreign learners. They hardly master the writing skills while learning English as a second language. The complexity always exists in the development of generating ideas rather than undertaking the process of translating such ideas in a readable form is considered the hardest phenomena. An intricacy becomes larger if ESL students are weaker. Coffrey (1987) highlights that writing or speaking are vital factors of communications in such process since individual express borrowed ideas, intentions or hopes and try to find others. Subsequently, the main theme of learning writing is to create communicative expertise. That means ESL learners can constitute language components affectively and ideas or thoughts openly to communicate very well with others. At every stage, an ESL learner faces difficulty, specially in the process of essay writing. The reason behind this is that essay writing is lengthier,harder and more difficult than writing a short paragraph. Widdowson (1978) opines that writing is called an art of constituting correct sentences and transforming them via visual levels of marks on a piece of paper. Whenever an individual tries to achieve such a goal, he faces a lot of challenges,such as grammatical, lexical or syntactic expertises that are supposed to daunt the learners on the spot. probability. As a matter of fact, in rare cases, written words are tolerable track of communication. Ulijn and strother (1995) concludes that the process of writing is considered significant cohesive skills in the development of language learning for the students of second language. As focusing on universities in our country Pakistan, all the universities consider that the writing skill plays an essential role in the academia. A lot of research has been conducted on the writing skills. It is included in all walks of life. For instances, in handouts, in writing compositions, in answering questions and in writing experimental reports etc.

\section{CHAPTER 2}

\section{LITERATURE REVIEW}

Most of teachers and educators have been concerning all over the world about mistakes and errors committed by L2 learners in second language or foreign language learning development. Errors have been integral section of learning process. They may lead students towards negative or positive feedbacks given by their teachers. Salem (2003) gives opinions that errors have always been fundamental part of learning development in L2 and they show output by learners. Alhaysony (2012) views that in the world of technology errors are analyzed by scores of electronic devices. Students are also supposed to check their mistakes themselves by using different electronic devices. Students who major in English writing try to avoid errors. It has been fruitful and significant for them. Aloe (2011) gives opinions that error correction process has been giving positive benefits to L2 learners. One of the studies conducted by Hasyin (2002) concluded that teachers as well as learners have been getting a lot of information while analyzing certain types of mistakes or errors. This process has always been beneficial for both students and teachers. Abi Samra (2003) figures out that we have been given a huge information by errors in the process of learning strategies, especially when we are going to use such kind of errors to investigate the pedagogical issues that can be causes behind such errors. Thus, we are able to predict potential difficulties in the written text by L2 learners. It happens when the students are supposed to appear in their exams related to English course that is the most precious part of learning. Then teachers are able to use useful material as well as healthy activities that are the need of students. A lot of definitions of errors exist. Richard (2002) gives suggestions that during the speaking and writing the second language or foreign language, errors come into the category of linguistics. If such kind of errors committed by a fluent or native speaker are considered as a fault or incorrection. Hence, if we want to explain or describe errors, it will be amazing way to work on error analysis in a second language or foreign language. Hasyin (2002) describes that error is an item of language that is not taken lightly and it leads to negative feedback among L2 learners or teachers. As a matter of fact, it leads to a production that always highlights incomplete or incorrect learning. Furthermore, Sridhar (1981) stressed on Corder's difference between errors and mistakes. Corder believes that mistakes are committed because of deviations relating to performance factor such as memory restrictions (eg. Almost mistakes are found in tenses or lengthy structures where subject-verb agreement issue exists, spelling, fatigue, emotions based on strain). These kind of mistakes are easily corrected by a reader during reading the text when he/she gives due attention to them.On the other hand, errors are observed in a systemic way.It is a frequent process as well consistency in the 
form of deviances regarding linguistic system in the process of learning. AbiSamra (2003) says error analysis is a kind of linguistics that targets errors which are committed by L2 students. Moreover, Alhaysony (2012) describes that the process of analyzing errors is an amazing way to describe or explain errors that are committed by students of L2 learners. While applying this type of strategy we can unveil the causes of students' frequent errors. Then, it will be much easier to declare the remedy, or other possible ways for future directions. Vahdatinejad (2008) suggests that the major purpose of error analysis is to know what kind of things should be taught to L2 learners. While investigating errors we are able to know what is required in a learner's competence. Such kind of information has been investigated by Sridhar (1981). Errors analysis is a crucial factor that should be explored to show us what strategies need to be applied in the second language learning. Again, investigated by Sridhar (1981) regarding EA, by investigating different difficult areas that are faced by student of L2 learners, it would be useful to learners: (A) defining the flow of presentation which is supposed to be targeted in the books in classrooms. (b) Finding out level that need to be emphasized explaination or practice is required to see a couple of items in a language that is supposed to be learned (c) distributing various lessons or a couple of exercises (d) choosing material to assess the students' proficiency. The current idea is supported by Hourani (2008) who declares that a huge information can be achieved while working on error analysis. That is not only very useful for teachers but also learners. and teachers will be able to correct errors and improve their methods of teaching. A lot of researchers conducted different studies globally to know valid ways of errors committed by second language or foreign language students. Such kinds of efforts are applied to properly know the real sources of errors or to provide reliable material for language learning. Rostami (2015) investigated $100 \mathrm{EFL}$ students' written texts. The analysis concluded that the main reasons behind errors were: little exposure to learning and lack of expertise in the target language. Al-Khatib et al (2014) investigated the parts of trouble in ESL. learning at Arab Open University Lebanon branch, the total number of participants was 169. All were enrolled in English communication course. The tasks that were given to L2 learners were reading comprehension, grammar test and writing a paragraph to know the difficulty from all the aspects of language. Out of 160, 154 were investigated with systematic errors including mistakes. Systematic errors were categorized in four kinds: emissive, additive, substitutive including word order. Others such as data manifesting. Local errors had been categorized in the language part: grammatical errors, syntactic errors, vocabulary and lexical. The restricted competency might lead to different areas of difficulty. On different places, third person singulars, auxiliaries and articles were incorrectly used. There was possibility that students might make mistakes while applying rules of L2 language learning. It may happen due to impact of the first language. During language learning, spelling mistakes cause a lot of issues in two directions: learners are supposed to identify a word by its sound. Then, they were not able to write properly. Learners can try to spell in phonetical way but cannot produce correct orthographic spelling because English alphabet was not similar. A big explanation pertaining to preposition by Sawalmeh (2013) has given a good results about errors including 32 essays that were written by 32 participants. All were males from Saudi Arabia. Their native language was Arabic. The errors found in written essays were investigated and categorized in different positions. This research showed that there were ten kinds of errors found in the written essays: "verb-tense, word order, singular/plural form, agreement of subjectverb, double negative, a couple of spelling mistakes, capitalization, use of articles, and the prepositions. Ridha (2012) conducted study over 80 students whose native language was not English. All were from college side. A researcher categorized errors in these categories: grammar errors, lexical, semantic and word order. It was found that most of the learners made mistakes or errors due to influence of their mother tongue because they were trying to translate the ideas into their native language.

\subsection{CLASSIFICATION OF ERRORS}

It this research, all the errors found in written work of learning English as ESL and EFL have been analyzed, and, then categorized. According to Dulay and Krashen (1982), research is available in six categories: (1) omission of grammatical morphemes (2) adding semantic features two times (3) using irregular verbs (4) using wrong words (5) using more than two forms (6) disarrangement of structures. In 1990, one researcher named James (1998) mentioned five categories about errors. They were: (1) errors related to grammar such as "adjectives, adverbs, articles, nouns, possessions, pronouns, prepositions, and verb" (2) substance errors such as capitalization, use of punctuation and spelling, (3) lexical errors such as formation of words and selection of the words, (4) errors relating to syntax "coordination or subordination, structures of sentences and order of sentences" (5) errors about semantic "ambiguous communication and miscommunication." There are several studies on this topic. One of them by Hengwichitkul (2006) investigated errors and, then, analyzed them in sentence level. All were categorized in different levels. For example, agreement of subject with verb, using different tenses, parts of speech, using participle phrases, relative clauses, active and passive voice, parallel structures, punctuations and fragments. According to Runkati (2013), errors have been categorized in main two levels: firs one was related to errors at the sentence level. For example, use of fragments, run-ons, agreement of 
subject with verb, order of verb, using different tenses, wrong use of capital letters and punctuations. The Second was to deal with the word level. For example, articles, prepositions, choosing words, nouns and numbers. This study went through error analysis in the second language all the errors that were based on sentential level other side word level was also investigated. The errors included in sentential level were: fragments, agreement of subject with verb, word order, using various tenses, wrong usage of capitalization along with punctuations. The word level errors including improper usage of articles indefinite and definite, wrong usage of preposition, choosing words, noun, pronouns and last one was verb. There are also certain types of analysis that have been adopted for instance; addition and omission were kept on sub-category regarding sentential errors las one word level errors.

\section{CHAPTER 3}

\section{RESEARCH METHODOLOGY}

\subsection{INTRODUCTION}

In this research the mixed method has been used.Obviously, this research comprises both qualitative and quantitative methods. Quantitative research was applied in the academic essays and the the qualitative research was applied I the semi-structured interviews.

\subsection{PARTICIPANTS}

The participants of this research were comprised of 60 L2 learners who were enrolled in HSC part 1 and 2, and, were, almost, 17 to 19 years old. The researcher selected them from the six most important colleges belonging to both urban and rural Sindh.

Three college were from urban Sindh and the three were from rural Sindh. The names of the colleges of rural Sindh were Ustad Bukhari Degree College Dadu, Government Girls Degree College Dadu, Government Degree College Nasirabad district Kamber Shahdadkot.Names of the colleges belonging to Urban sindh were ,Government Sindh Commerce College Hyderabad,Government Boys Degree College Qasimabad Hyderabad and Government Girls Degree College Hyderabad

For this study, I selected participants from six colleges of Sindh, Pakistan. Among them, three colleges were selected from rural Sindh and same number was selected from Urban Sindh. Total 60 students were selected. Ten participants from each of the colleges belonging to both rural and urban Sindh. The names of the colleges were Ustad Bukhari Degree College Dadu, Government Girls Degree College Dadu, Government Degree College Nasirabad district Kamber Shahdadkot.Names of the colleges belonging to Urban sindh were ,Government Sindh Commerce College Hyderabad,Government Boys Degree College Qasimabad Hyderabad and Government Girls Degree College Hyderabad

Majority of participants speak Sindhi and Urdu at their respective homes. My focus was on the errors related to prepositions, articles, adjectives, pronouns, conjunctions, verb to be, nouns, numbers and punctuations.

Moreover, I made two separate groups. I put all participants of Rural Colleges in group I and Urban students in group II during comparison between the errors of rural and urban ESL/EFL learners in Sindh, Pakistan.

\subsection{PROCEDURE OF DATA COLLECTION}

The task of writing assignments was given to all 60 participants. The task was based on essay writing. They were asked to write a report comprising 200-250 words on the topic named "Why do I love My College?" The duration was only 60 minutes. All were guided before writing. All students were directed to be include in their responses. After collecting the essays, they were typed in MS word 2010 to make them computer readable. Finally, three steps given by Corder (1974) were followed: (1) collecting sample of errors (2) identifying errors (3) describing errors. 


\subsection{INSTRUMENTS}

\subsubsection{Essay Writing}

All the students were asked to write an essay comprising of 200-250 words on the given topics. The writings of 60 students were selected for the purpose of the sample study.All the participants were male as well as female students chosen randomly from each of the six colleges. The participants were given a task in form of an assignment that was based on "essay writing" they had to write a report entitled "Why do I love My College?" The duration was only 60 minutes, all the participants were informed to include precise detail in their essays.

\subsubsection{Semi-structured Interviews}

Semi-structured interviews were conducted for examining teachers' attitudes and beliefs regarding their students' writing skills. At least 20 experienced English teachers aged 35 to 50 were selected while using purposive sampling techniques for semi-structured interviews for RQ no 3.The semi structured interview protocols were used. It got information about the teachers' perceptions and roles regarding the the academic and social environment and their effects on learner's skills pertaining to second language learning. The semistructured interviews were conducted from the teachers of English language from the selected colleges in order to know the teachers' perceptions and views regarding the causes of errors. For this purpose, twenty English language teachers were selected from the colleges.

\subsection{DATA ANALYSIS PROCEDURE}

All the collected data was analyzed in different ways. In the first, phase errors were identified and classified while using Markin software. Further, analysis of errors was statically done in effective ways (Darus, 2007). In the second phase, errors were counted for quantitative analysis. The errors were counted and, then, were analyzed by using SPSS software in order to compare and contrast the errors committed by different students from the rural and urban students at HSSC level.

In the third phase, qualitative data was analyzed applying content analysis method that is very authentic method to get qualitative data. The interviews were transcribed while using computer software. The content analysis method was applied for the semi-structured interviews.

\subsection{RESEARCH ETHICS}

Before collecting data, prior permission was got from the administration of selected colleges of Sindh. They were informed about the research study, its aim and objects as well as its implications. They were promised that no any information would be disclosed. The students were also informed about the research study.

All the participants were informed about the purposes of their interviews, given explanation pertaining to topic "Classroom-based Assessment).They were told about expected questions. Finally, the interview protocol was given to them along with necessary information. All the ethics of research were applied while informing them.

\subsection{LIMITATIONS OF THE STUDY}

The critical theme of this study was to analyze various kinds of grammatical errors committed by HSSC students in Sindh. At initial stage, all the participants were informed about the main purposes of writing. The researcher collaborated with all his colleagues who helped him in supervision of the students. when the writing essay process was going on, the table of classification was given in advance to teachers (see appendix 4) for counting grammar errors. Such process took a lot of time. The accuracy of errors was measured in the form of revising various kinds of errors. Finally, the researcher counted the frequencies and arranged them.Regarding limitation of this study, the number of participants was fewer as compared with other existing studies that might not lead to generalization of these findings. The current research deals only with the limited number of participants pertaining to the linguistic errors.Moreover,it involved less time and apace. This study filled the gapes of students studying in only government colleges of Sindh, Pakistan because competencies may show some differences between private and the mentioned government colleges. The finding of this study might not be fruitful for private colleges of Sindh. Future direction is clear for other researcher to investigate other flaws of students in their writing skills. For example, unity,coherence and others. Moreover, it is the need of hour to conduct various types of researches on private colleges of Sindh, Pakistan. 


\section{CHAPTER 5}

\section{CONCLUSION AND FUTURE RESEARCH}

\subsection{CONCLUSION}

There is no doubt that error analysis has been one of the critical subjects of the student's teachers and policymakers. They have always been in the search of the fact that correct, accurate and error-free English should be written. But the trouble is that the under privileged and the disadvantaged such as the people belonging to the rural areas has got fewer facilities and privileges. This research has found out that the language learners and students belonging to rural Sindh commit far more errors than their urban counter parts. This research has successfully found out the fact that the students of rural areas commit many written errors such as punctuations, subject-verb-agreement,tenses, active and passive voice, spellings and many many more. On the other hand, the students belonging to urban areas commit ,more or less, the same errors,But the number of errors committed by them is much fewer than their rural counter parts. The reason is that their more linguistically privilidged.In addition, the first language does not influence them much because of greater and sounder exposure the the English language. On the contrary, The rural students are,to a great extent, deprived of all this.

As far the benefits of this research,it will certainly prove to highly beneficial for urban and rural students including policy makers in the trying,testing and hard times to come. The students will be be able to know their short comings in composition. Then,naturally,they will try to avoid them. Thus, the written skill will be getting better and better. Finally, the policy-makers will be able to formulate such policies that will be better for students. In this way, we will be able to live up to the demands of the modern times.

\section{REFERENCE}

Ahmed (2016) Analysis: A study of Pakistan second language learners' written compositions, Gomal University Journal of Research, Special Issue II, June, 2016, ISSN: 1019-8180.

Brown, H. D. (1980). Principles of language learning and teaching (4th ed.). Englewood Cliffs, NJ: PrenticeHall.

Carrington (2005)."Academic Literacy in a wired world: Redefining genres for college.

Corder, S. P. (1967).The Significance of Learners' Errors. International Review of Applied Linguistics in Language Teaching, 5(1-4), 161-170.

Corder, S. P. (1975).Error Analysis, Interlanguage and Second Language Acquisition. Language Teaching, 8(04), 201-218.

Crystal, D. (2003). Dictionary of linguistics and phonetics John Wiley \& Sons., 30.

Crsytal, D. (1995) Language Play. London: Penguin Books.

Crsytal, D. (1997) English as a global Language.

Crystal, D. (2007). Txtng: The Gr8 Db8. Oxford: Oxford University Press.

Crystal, D. (2008). Txtng: The Gr8 Db8. Oxford: Oxford University Press.Cup levinson.

Foppoli, J. (2011). Is grammar really important for a second language student? Retrieved on January 10, 2015 from http://www.eslbase.com/articles/grammar.

James, C. (2001). Errors in language learning and use: Exploring error analysis. Beijing: Foreign Language Teaching and Research Press.

Jamil (2016) Analyzing Common Errors in English Composition at Postgraduate Level in Khyber Pakhtunkhwa (Pakistan). 
Karra, M. (2006). Second Language Acquisition: Learners' Errors and Error Corazrection in Language Teaching. Translation Theory, Translator Education.

Khaled (2017) A longitudinal Analysis study of writing errors made by EFL students at Al-Qudus University. British Journal of Education Vol.5, No.13, pp.127-145, December 2017.

Rahman, T. (2003).Language-teaching and power in Pakistan. Pakistani languages and society: problems and prospects, $1-18$.

Rahman, T. (2005). Passports to privilege: The English-medium schools in Pakistan. Peace and Democracy in South Asia, 24-44. 